\title{
Abscessos dentários periapicais em leitões com síndrome multissistêmica do definhamento ${ }^{1}$
}

\author{
Felipe L. Koller², Sandra M. Borowski ${ }^{3}$, William Asanome², Gisele Hein ${ }^{2}$, \\ Franco L. Lagemann², David Driemeier ${ }^{4 *}$ e David Emilio S.N. de Barcellos ${ }^{2}$
}

ABSTRACT.- Koller F.L., Borowski S.M., Asanome W., Hein G., Lagemann F.L., Driemeier D. \& Barcellos D.E.S.N. 2008. [Dental periapical abscesses in piglets affected by postweaning multisystemic wasting syndrome PMWS.] Abscessos dentários periapicais em leitões com síndrome multissistêmica do definhamento. Pesquisa Veterinária Brasileira 28(6):271-274. Faculdade de Veterinária, Universidade Federal do Rio Grande do Sul, Av. Bento Gonçalves 9090, Porto Alegre RS 91540-000, Brazil. E-mail: davetpat@ ufrgs.br

Swine producers have historically resected needle teeth of newborn pigs to prevent potential injuries to the sow mammary gland and faces of littermates. However, the possible impact of this practice on pig performance has been questioned. As part of a study, 280 PMWS affected piglets, with 40-70 days of age, were examined for the presence of dental lesions immediately after euthanasia. Most pigs were confirmed as PMWS by the detection of typical microscopic lesions and immunohistochemical pattern. At least one periapical abscess was observed in 58 piglets $(20.7 \%)$, of which 12 had multiple abscesses. There were $22(31.4 \%), 16(22.9 \%), 4(5.7 \%), 23(32.9 \%)$, and $5(7.1 \%)$ abscesses in $3^{\text {rd }}$ upper incisives, $3^{\text {rd }}$ lower incisives, upper canines, lower canines, and other teeth, respectively. The higher prevalence of dental abscesses observed in $3^{\text {rd }}$ incisives and lower canines is probably associated with the wider area of grinding or clipping to which these teeth were subjected. Among bacteria isolated from samples collected from 65 abscesses, Streptococcus sp. was the most prevalent bacteria and was present in $21.48 \%$ and $27.7 \%$ of the aerobic and anaerobic isolates, respectively. In the second most frequent group were coryneform microorganisms, which showed higher rate of isolation under anaerobic atmosphere than in aerobic culture. There was preponderance of Gram-positive isolates. It could not be determined whether these bacterial co-infections predisposed pigs to development of PMWS-type lesions or if were subsequent to the PCV2 infection.

INDEX TERMS: Periapical abscess, causal bacteria, co-infection, PMWS, piglet, teeth resection, teeth clipping.

RESUMO.- Duzentos e oitenta leitões, entre 40 e 70 dias de idade, afetados pela sindrome multissistêmica do definhamento (SMD) foram examinados após eutanásia para pesquisa de lesões dentárias. Pelo menos um abs-

\footnotetext{
${ }^{1}$ Recebido em 11 de setembro de 2007.

Aceito para publicação em 15 de janeiro de 2008.

2 Setor de Suínos, Faculdade de Veterinária, Universidade Federal do Rio Grande do Sul (UFRGS), Av. Bento Gonçalves 9090, Porto Alegre, RS 91540-000, Brasil. E-mail: davidbarcellos@terra.com.br

${ }^{3}$ Laboratório de Bacteriologia, Centro de Pesquisas Veterinárias Desidério Finamor (IPVDF), Estrada do Conde 6000, Eldorado do Sul, RS 92900-000, Brasil.

${ }^{4}$ Departamento de Patologia Clínica Veterinária, UFRGS, Porto Alegre, RS. *Autor para correspondência: davetpat@ufrgs.br
}

cesso periapical foi observado em 58 leitões $(20,7 \%)$, dos quais 12 apresentaram abscessos múltiplos. Terceiros incisivos superiores, $3^{\text {os }}$ incisivos inferiores, caninos superiores, caninos inferiores e outros dentes apresentaram respectivamente $22(31,4 \%), 16(22,9 \%), 4(5,7 \%)$, $23(32,9 \%)$ e $5(7,1 \%)$ abscessos periapicais. A maior prevalência de abscessos observada nos dentes $3^{\text {os }}$ incisivos e caninos inferiores está provavelmente associada com a maior área de corte ou desgaste que sofrem esses dentes. Entre as bactérias isoladas de amostras de 65 abscessos, Streptococcus sp. foi a mais prevalente e esteve presente em $21,48 \%$ e $27,7 \%$ dos isolados em aerobiose e anaerobiose, respectivamente. Na segunda posição em prevalência estiveram as bactérias corineformes, 
as quais foram mais freqüentemente isoladas em atmosfera anaeróbica do que aeróbica. Houve preponderância de isolamentos de bactérias Gram-positivas. Não foi possível determinar se as co-infecções bacterianas predispuseram às lesões características de SMD ou foram conseqüentes à imunossupressão causada pela infecção com PCV2.

TERMOS DE INDEXAÇÃO: Abscesso periapical, bactérias, coinfecção, corte de dentes, leitão, ressecção dentária, SMD.

\section{INTRODUÇÃO}

O corte ou desgaste dos dentes de leitões recém-nascidos ( $3^{\circ}$ incisivos e caninos) é uma prática comum que visa reduzir a prevalência de lesões cutâneas (leitões) e mamárias (matrizes). Essa prática de manejo é realizada nas primeiras horas de vida e pode causar remoção ou fratura do esmalte dentário e, assim, predispor à infecção bacteriana, através dos túbulos dentinários ou por exposição pulpar direta. Tais infecções podem evoluir para abscessos periapicais, importantes causas de refugagem de leitões (Barcellos 1990). A síndrome multissistêmica do definhamento (SMD) é associada com a infecção pelo circovírus suíno 2 e com outros fatores relacionados ao manejo (Rose et al. 2003). A associação de SMD com coinfecções tem sido freqüentemente descrita (Segalés \& Domingo 2002, Ellis et al. 2004, Zlotowski et al. 2006) e a ocorrência de infecções dentárias é compatível com tal condição. Esse trabalho apresenta a prevalência de abscessos periapicais nos diferentes grupos dentários de leitões afetados por SMD, bem como resultados de culturas bacteriológicas de amostras dessas lesões.

\section{MATERIAL E MÉTODOS}

Como parte de um estudo, 280 leitões de creche, entre 40 e 70 dias de idade, provenientes de três agroindústrias do Rio Grande do Sul e com atraso de desenvolvimento compatível com SMD foram examinados para detecção de lesões dentárias. A SMD foi subseqüentemente confirmada pela detecção de lesões microscópicas características e imunoistoquímica anti-PCV2 (Sorden 2000) em fragmentos de linfonodos de 184 leitões. Os animais foram examinados imediatamente após eutanásia, em sete sessões de necropsia, no período de 11 de outubro 2004 a 17 de janeiro 2005.

Para o exame dos dentes inferiores, a mandíbula foi separada do restante da cabeça e foram feitos cortes seriados, com o podão, no sentido dorso ventral, caudalmente ao ponto de eclosão de cada dente. Os dentes superiores foram examinados aos pares, com cortes iniciados caudalmente ao dente alvo. A prevalência de abscessos periapicais foi determinada pela visualização de lesões macroscópicas purulentas no interior do canal pulpar (base) ou difundidas para a região óssea peripulpar. Nos casos em que a difusão do abscesso atingia mais de um dente, foi considerado apenas o dente com lesão abscedativa maior. Abscessos múltiplos foram registrados quando dois ou mais dentes, ou grupo de dentes no caso de difusão, foram observados em um mesmo animal.

Amostras do material purulento de 65 dos 70 abscessos observados foram coletadas com agulhas estéreis, armazena- das em refrigeração e processadas (bacteriologia) em até 96 horas. Amostras dos cinco abscessos restantes não foram coletadas porque houve contaminação grosseira durante a necropsia. O plaqueamento foi realizado em ágar sangue (AS) e ágar Mac Conkey (Mac), mantidos em aerobiose (AS e Mac) e anaerobiose (AS), a $37^{\circ} \mathrm{C}$. A incubação em anaerobiose foi feita em jarra tipo Mc Intosh - Fieldes, em atmosfera de $10 \% \mathrm{CO}_{2}$, $10 \% \mathrm{H}_{2}$ e $80 \% \mathrm{~N}_{2}$, com catalisador de paládio. A leitura foi realizada após 48 horas. As bactérias que apresentaram crescimento significativo (mais de $80 \%$ de colônias com características semelhantes) foram submetidas à classificação bioquímica (Barrow \& Feltham 1999).

\section{RESULTADOS}

Cinqüenta e oito $(20,7 \%)$ dos 280 leitões examinados apresentaram pelo menos um abscesso periapical, 12 tinham abscessos múltiplos. As lesões se distribuíram com maior freqüência nos dentes que foram cortados ou des-

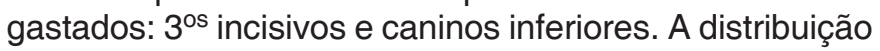
de abscessos periapicais nos diferentes grupos dentários está apresentada no Quadro 1. Streptococcus sp. (em aerobiose e anaerobiose) e corineformes (em anaerobiose) foram as bactérias mais freqüentemente isoladas das amostras de abscessos periapicais. Os resultados obtidos na bacteriologia são mostrados no Quadro 2.

\section{DISCUSSÃO}

Fatores associados com a necessidade do corte de dentes de leitões e com as variações de prevalência de lesões causadas não estão completamente determinados

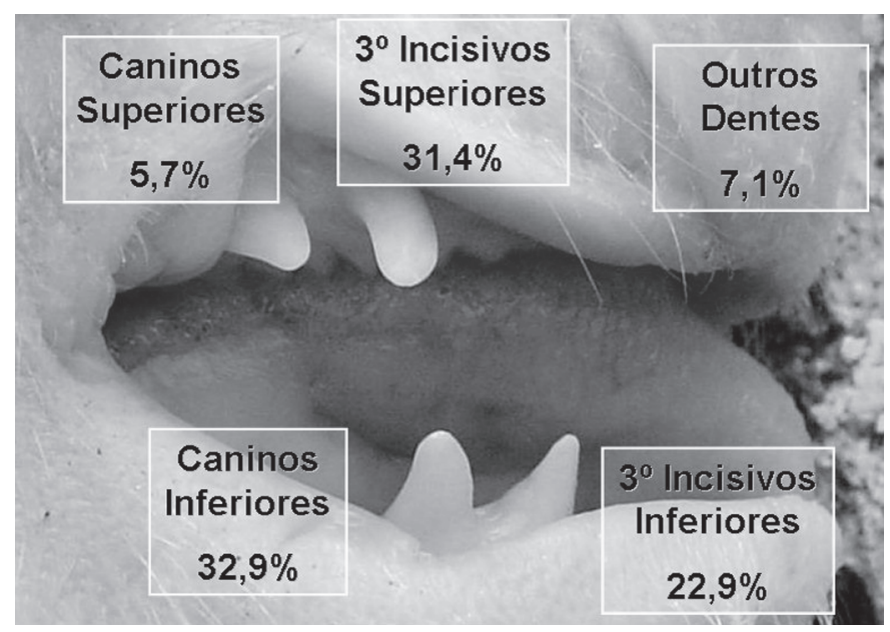

Fig.1. Dentição de leitão recém-nascido. Distribuição percentual de 70 abscessos periapicais observados em leitões afetados por Síndrome Multissistêmica do Definhamento (SMD).

Quadro 1. Distribuição e freqüência de abscessos periapicais nos diferentes grupos dentários de 58 leitões afetados pela SMD

\begin{tabular}{ccccc}
\hline \multicolumn{2}{c}{$3^{\text {os }}$ Incisivos } & \multicolumn{2}{c}{ Caninos } & Outros dentes \\
\hline Superiores & Inferiores & Superiores & Inferiores & \\
$22(31,4 \%)$ & $16(22,9 \%)$ & $4(5,7 \%)$ & $23(32,9 \%)$ & $5(7,1 \%)$
\end{tabular}




\section{Quadro 2. Freqüência de bactérias isoladas de amostras de 65 abscessos periapicais observados em 58 leitões afetados por SMD}

\begin{tabular}{lcccccc}
\hline \multicolumn{1}{c}{ Bactérias } & $\begin{array}{c}\mathrm{AS}^{\mathrm{a}} \\
\left(\mathrm{O}_{2}\right)\end{array}$ & \multicolumn{7}{c}{$\%$} & $\begin{array}{c}\mathrm{AS} \\
\left(\mathrm{ANO}_{2}\right)\end{array}$ & $\%$ & $\mathrm{Mac}$ & $\%$ \\
& 1 & 1,54 & 6 & 9,23 & 0 & 0,00 \\
Streptococcus NH & 12 & 18,46 & 9 & 13,85 & 0 & 0,00 \\
Streptococcus Alfa & 1 & 1,54 & 3 & 4,62 & 0 & 0,00 \\
Streptococcus Beta & 6 & 9,23 & 2 & 3,08 & 0 & 0,00 \\
Proteus sp. & 3 & 4,62 & 5 & 7,69 & 0 & 0,00 \\
Arcanobacterium pyogenes & 1 & 1,54 & 2 & 3,08 & 0 & 0,00 \\
Escherichia coli & 1 & 1,54 & 0 & 0,00 & 0 & 0,00 \\
Pasteurella multocida & 1 & 1,54 & 10 & 15,38 & 0 & 0,00 \\
Bactérias corineformes & 8 & 12,31 & 6 & 9,23 & 0 & 0,00 \\
Microbiota mista & 4 & 6,15 & 3 & 4,62 & 0 & 0,00 \\
Cocos Gram+ & 1 & 1,54 & 1 & 1,54 & 0 & 0,00 \\
Cocos NH, Oxi- & 4 & 6,15 & 3 & 4,62 & 0 & 0,00 \\
Coliforme NH & 22 & 33,85 & 20 & 30,77 & 52 & 80,00 \\
Sem crescimento & 0 & 0,00 & 2 & 3,08 & 0 & 0,00 \\
Bastonetes Gram+ & 0 & 0,00 & 0 & 0,00 & 3 & 4,62 \\
Coliformes LF e LNF & 0 & 0,00 & 0 & 0,00 & 10 & 15,38 \\
Coliformes LF & & & & &
\end{tabular}

${ }^{\mathrm{a}} \mathrm{AS}=$ Agar Sangue, Mac $=$ Agar Mac Conkey, $\mathrm{O}_{2}=$ Aerobiose, $\mathrm{ANO}_{2}=$ Anaerobiose, $\mathrm{NH}=$ Não hemolítico, Alfa $=$ Alfa hemolítico, Beta = Beta hemolítico, Oxi = Oxidase negativo, LF = Lactose ferrmentativo, LNF = Lactose não fermentativo.

(Hutter et al. 1993, Meunier-Salaun et al. 2002, Estienne et al. 2003). Lesões dentárias tais como pulpites, periodontites e cáries têm sido observadas em suínos ao abate (Selegatto et al. 2003) e associadas com o corte ou desgaste de dentes de leitões (Hutter et al. 1993). Tais estudos incluíram lesões que podem evoluir para abscessos periapicais, os quais foram observados em $20,7 \%$ dos leitões do atual estudo. A maioria desses animais apresentava SMD (Sorden 2000), achado compatível com as descrições de co-infecções em animais afetados pela síndrome (Segalés \& Domingo 2002, Ellis et al. 2004, Zlotowski et al. 2006). Em animais sem sinais clínicos da SMD, em estudo realizado no Rio Grande do Sul (Nottar 2007), as lesões dentárias apresentaram-se em níveis bastante inferiores $(10,9 \%)$. Os $3^{\text {os }}$ incisivos e caninos inferiores apresentaram maior prevalência de lesões. Esses dentes são mais proeminentes na fase do manejo dentário, portanto sofrem maior área de corte ou desgaste e têm maior probabilidade de exposição da cavidade pulpar. Os caninos superiores, que estão menores na ocasião do corte, apresentaram prevalência de lesões semelhantes a dos demais dentes não cortados. Não foi possível determinar se as infecções dentárias foram causa ou conseqüência da SMD. Embora o corte e/ou desgaste dentários em associação ou não com a infecção por PCV2 possam ter predisposto os abscessos dentários, há também possibilidade de que a refugagem estivesse associada primariamente com as infecções dentárias (Barcellos 1990) ou outras causas não consideradas aqui.

As bactérias mais freqüentes nas amostras de abscessos periapicais pertenceram ao gênero Streptococcus que inclui espécies colonizadoras de mucosas, intestinos e pele de animais e que, sob condições apropriadas, po- dem oportunisticamente produzir doença (Timoney et al. 1988). Streptococcus sp., reconhecido patógeno oral (Oliveira 1995), freqüentemente está associado com processos piogênicos (Timoney et al. 1988), característica compatível com os resultados constatados. Espécies de bactérias corineformes têm sido classificadas como patógenos oportunistas ou obrigatórios de humanos (Funke et al. 1997), plantas e animais (Holt et al. 1994). Esses organismos, os quais têm sido objeto de ampla reclassificação (Funke et al. 1997), ocuparam a segunda posição em freqüência nas amostras estudadas.

Nesse estudo, se empregou o critério da predominância de tipo colonial para determinar a bactéria causal. Microbiota mista foi identificada em $12,31 \%$ dos cultivos aeróbios e 9,23\% dos anaeróbicos. Os abscessos periapicais em humanos são freqüentemente associados com infecções mistas, especialmente agentes anaeróbios (Albuquerque et al. 2005). A considerável ocorrência de amostras com isolamento negativo em aerobiose (34\%) e anaerobiose (31\%) pode estar associada com antibioticoterapia, morte de bactérias em lesões crônicas ou com problemas na coleta e/ou remessa das amostras, em parte porque meios de transporte apropriados para anaeróbios (Hill 1978) não foram utilizados.

\section{REFERÊNCIAS}

Albuquerque D.S., Diniz A.S. \& Matheus T.C.U. 2005. Considerações clínicas sobre a microbiota endodôntica. Disponível em: < http:// www.cro-pe.org.br/revista/rev1099/artigo5.html > Acesso em 23 junho 2005.

Barcellos D.E.S.N. 1990. Etiological analysis of a problem of runt pigs in the nursing period, in an industrial pig herd. Proc. 11th Int. Pig Vet. Soc. Congr., Lausanne, Switzerland, p.384.

Barrow G.I. \& Feltham R.K.A. 1999. Cowan and Steel's Manual for the Identification of Medical Bacteria. 3rd ed. Cambridge University Press, Cambridge. 331p.

Ellis J., Clark E., Haines D., West K., Krakowka S., Kennedy S. \& Allan G.M. 2004. Porcine circovirus-2 and concurrent infections in the field. Vet. Microbiol. 98(2):159-163.

Estienne M.J., Horsley B.R. \& Harper A.F. 2003. Case study: effects of pig needle teeth on pig and sow injuries and pre-weaning pig performance. Disponível em http://64.241.242.253/p/articles/ mi_qa4035/is_200302/ai_n9193241/pg_1. Acesso em 6.9.2006.

Funke G., Von Graevenitz A., Clarridge III J.E. \& Bernard K.A. 1997. Clinical Microbiology of Coryneform Bacteria. Clin. Microbiol. Rev. 10(1):125-159.

Hill G.B. 1978. Effects of storage in an Anaerobic Transport System on bacteria in known polymicrobial mixtures and in clinical specimens. J. Clin. Microbiol. 8(6):680-688.

Holt J.G., Krieg N.R., Sneath P.H.A., Staley J.T. \& Williams S.T. 1994. Bergey's Manual of Determinative Bacteriology. 9th ed. William \& Wilkins, Baltimore, p.1266-1283.

Hutter S., Heinritzi K., Reich E. \& Ehret W. 1993. Effects of different methods of tooth resection in suckling piglets. Tierärztl. Prax. 21(5):417428.

Meunier-Salaun M.C., Bataille G., Rugraff Y. \& Prunier A. 2002. Influence of tail docking and tooth resection on behavior and performance of piglets. J. Anim. Sci. 80(1):371.

Nottar E. 2007. Avaliação de causas de baixo desenvolvimento em suínos nas fases de recria e terminação. Dissertação de Mestrado 
em Sanidade Suína, Curso de Pós Graduação em Ciências Veterinárias, Universidade Federal do Rio Grande do Sul, Porto Alegre, RS. $52 p$.

Oliveira S.J. 1995. Guia Bacteriológico Prático: microbiologia veterinária. Editora ULBRA, Canoas. 142p.

Rose N., Larour G., Le Diguerher G., Eveno E., Jolly J.P., Blanchard P., Oger A., Le Dimma M., Jestin A. \& Madec F. 2003. Risk factors for porcine post-weaning multisystemic wasting syndrome (PMWS) in 149 French farrow-to-finish herds. Prev. Vet. Med. 61(3):209-225.

Segalés J. \& Domingo M. 2002. Postweaning multisystemic wasting syndrome (PMWS) in pigs: A review. Vet. Quart. 24(3):109-124.

Selegatto M.A., Carvalho L.F.O.S., Oliveira C.J.B., Domingues Jr F.J.
\& Taveira, R.S. 2003. Ocorrência de cárie em suínos de abate. Anais 11ํㅡㅁ. Bras. Vet. Espec. Suínos. Abraves, Concórdia, p.157-158.

Sorden S.D. 2000. Update on porcine circovirus and postweaning multisystemic wasting syndrome (PMWS). Swine Health Prod 8:133136.

Timoney J.F., Gillespie J.H., Scott F.W. \& Barlough J.E. 1988. Hagan and Brunner's Microbiology and Infectious Diseases of Domestic Animals. 8th ed. Comstock Publishing Associates, London. 951p.

Zlotowski P., Rozza D.B., Pescador C.A., Barcellos D.E., Ferreiro L., Sanches E.M. \& Driemeier D. 2006. Muco-cutaneous candidiasis in two pigs with postweaning multisystemic wasting syndrome. Vet. J. 171(3):566-569. 